\title{
Evaluation of Aquifer Characteristics in Echi, Delta State, Nigeria Using Well Logging and Pumping Test Method
}

\author{
Ochuko Anomohanran \\ Department of Physics, Faculty of Science, Delta State University, Abraka, Delta State, Nigeria
}

Received 2013-08-05, Revised 2013-08-19; Accepted 2013-09-02

\begin{abstract}
This study was carried out to evaluate the aquifer characteristics of groundwater at Echi, Delta State, Nigeria. This was carried out by conducting electrical resistivity and spontaneous potential loggings in a drilled well at the study location. Pumping test using a one kilowatt pumping machine was carried out in the well. The logs were interpreted while the record of the pumping test was analysed using the Jacob straight line method. The result showed that five lithologic formations which are lateritic sand, clay, fine sand, medium grain sand and coarse sand exist in the area and that groundwater exist in the third, fourth and fifth formations. The analysis of the log record showed that the water quality increased with respect to the depth of the well. The value of the conductivity of the aquifer obtained from the analysis of the log record was $5.8 \times 10^{-3} \mathrm{mS} / \mathrm{m}$ while the transmissivity was obtained as $86.0 \mathrm{~m}^{2} /$ day. The specific capacity of the aquifer was obtained as 0.258 . These values obtained from the test well revealed that the aquifer contained good quality water suitable for drinking and other purposes.
\end{abstract}

Keywords: Pumping Test, Transmissivity, Conductivity, Specific Capacity, Ground Water

\section{INTRODUCTION}

The quest for good quality water suitable for drinking, irrigation, livestock watering and other uses have made groundwater inevitable as a source of uncontaminated water (Uto et al., 2012). Groundwater is explained as that part of precipitation that enters the ground and percolates downward through unconsolidated materials and openings in bedrock until it reaches the water table. This unconsolidated sediment that is capable of yielding water in usable quantities is referred to as aquifer (Alabi et al., 2010).

Aquifer properties which are known to affect groundwater availability include aquifer thickness and the size and degree of interconnection of pore spaces within the aquifer material. These properties affect the ability of an aquifer to store and transmit groundwater (Anomohanran, 2013a). Groundwater is explored using a number of geophysical techniques which include electrical resistivity, seismic and magnetic
(Anomohanran, 2013a). The use of a particular geophysical technique depends on the geological settings (Anomohanran, 2013b).

In order to guarantee quality groundwater, it is important to integrate a number of aquifer parameters determined from borehole loggings and subsurface resistivity parameters (Uto et al., 2012). Borehole geophysical logging provides a highly efficient means of determining the character and thickness of the different geologic materials penetrated by wells and test holes. Kamble et al. (2012) asserted that borehole logging techniques are increasingly used to assess the geological risk associated with the construction of large power projects.

Borehole logging has evolved around meeting the needs of the petroleum industry with little development of specified tools for groundwater evaluation. These logs are generally used as pointers of clay or sand content. Khalil et al. (2011) revealed that well data and pumping test can be used to estimate shale size and hydraulic 
conductivity using a nonlinear regression technique. Well data which are generally used include gamma ray, spontaneous potential, resistivity, calliper and density logs (Khalil et al., 2011).

Resistivity logging is sometimes used in mineral exploration and water-well drilling but is most commonly used for formation evaluation in oil and gas well drilling. The use is essentially based on the principle that the material content of most rocks are insulators while the fluid contained in the rocks are conductors including water (Kamble et al., 2012). This is however not true for hydrocarbon liquids which are known to have very high resistivity. When a subsurface layer is porous and contains saline water, the overall resistivity will be low. Resistivity is a fundamental property of a material which represents how strongly a material opposes the flow of electric current. The resistivity logging is capable of estimating the resistivity of subsurface formation and identifies the nature and quality of subsurface geological strata (Kamble et al., 2009; 2012).

Spontaneous Potential (SP) log measures the chemical differences between two adjacent formations and the drilled well fluid. The SP log reading moves toward a positive position when clay or shale is encountered and move toward a negative position when sand or gravel is encountered (Kamble et al., 2012). Whenever there is a shift in the position of the plotted SP line, a change in formation composition has taken place. With the record of this log, the areas or zones containing sand and or gravel can be easily identified. The value of the electrical conductivity of the formation is a test of the characteristics of the water contained in the formation. In a nutshell, the SP scale indicates the type of water in the formation relative to the drilling fluid.

Groundwater level measurements can provide important information about the local groundwater resources. For instance, groundwater availability and estimates of aquifer yield are determined by analysing changes in water levels related to pumpage. The spatial mapping of water level elevation can permit the identification of regional groundwater flow direction as well as areas of recharge and discharge.

Pumping test according to Abdel-Aziz et al. (2009) is the standard technique for estimating various hydraulic conditions of aquifer systems. These include transmissivity, hydraulic conductivity, storage coefficient and leakance (Kamble et al., 2012). These are treated graphically to analyse the steady or unsteady drawdown pumping test data by using several nonlinear investigative models (Abdel-Aziz et al., 2009).
The water transmitting properties of an aquifer are expressed as hydraulic conductivity and transmissivity. Hydraulic conductivity is a measure of the rate that water will move through an aquifer. Transmissivity is equal to the hydraulic conductivity multiplied by the saturated thickness of the aquifer.

This study is therefore carried out to assess the groundwater quality by determining the aquifer characteristics of the area using well logs and pumping test. The study provides the conductivity variation of the formations in the study well to ascertain the quality of the groundwater in the various formations. This study will act as a starting point in the development of a data bank for assessing groundwater quality and also develop strategies to protect the aquifers from contamination.

\section{MATERIALS AND METHODS}

This study was carried out at Echi in Delta State, Nigeria situated on longitude $5.98^{\circ}$ East and latitude $5.70^{\circ}$ North (Fig. 1). The town is centrally located in Delta State and act as an agriculture hotspot in the State. It has been observed that many cash and food crops are grown in this area.

A well was drilled to a depth of $38 \mathrm{~m}$ from the ground level for the purpose of determining the aquifer characteristics of the area. Soil samples were collected at intervals to determine the various formations of the subsurface. These are put together to obtain the lithologic section of the area.

The electrical logging comprising of resistivity and spontaneous potential loggings was carried out in the drilled well. The instrument employed in the study is the SAS 1000 Terrameter together with SAS 200 logging probe and a tape. The probe was lowered into the well at various intervals of length beginning from $8 \mathrm{~m}$ depth and the resistivity and the spontaneous potential logs were obtained.

Pumping test was also carried out using a $1 \mathrm{~kW}$ pumping machine. The water in the well was pumped out at a constant rate of $190 \mathrm{~m}^{2} /$ day. For a specific interval of time, the depth of the water level from the surface was measured in metre. This was carried out until the water level became constant over a long period of time. At this point, the pumping machine was switched off and the aquifer allowed to recharge while the time and corresponding depth determined. The data obtained were subjected to graphical and analytical analysis to determine the conductivity, transmissivity and specific capacity of the aquifer. 


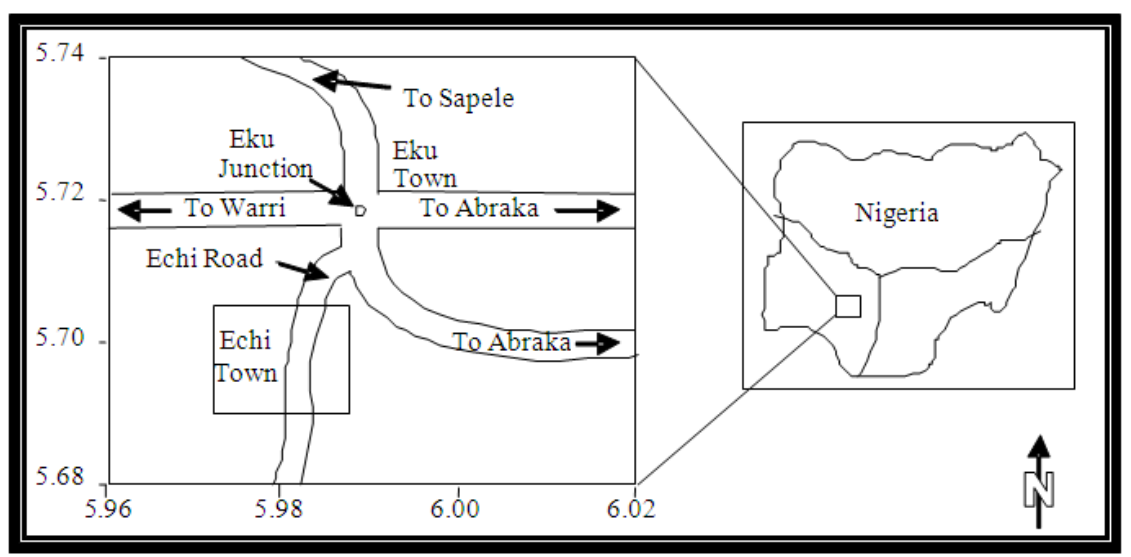

Fig. 1. Location Map of the Study Area

\section{RESULTS}

The lithologic formations encountered during the drilling process are presented in the log section as shown in Fig. 2. This was obtained from the core soil samples obtained in the process of drilling.

The result of the resistivity logging is as shown in Fig. 3 while the result of the spontaneous potential $\log$ is presented as Fig. 4. Figure 3 and 4 were used to estimate the hydraulic characteristics of the well and the result presented as shown in Table 1.

The plot of the well depth versus time obtained from the pumping test for discharge and recharge is presented as shown in Fig. 5. The drawdown calculated from the record of the pumping is plotted against the recorded time as shown in Fig. 6. It is important to note that the time is plotted on a logarithmic scale in line with Jacob's straight line method for pumping test data analysis for a confined aquifer (Majumdar and Das, 2011). Using the Jacob's straight line method, the Transmissivity (T) of the aquifer was determined using the relation:

$$
\begin{aligned}
& \mathrm{T}=\frac{2.3 \mathrm{Q}}{2 \pi \Delta\left(\mathrm{h}_{\mathrm{o}}-\mathrm{h}\right)} \\
& \mathrm{S}=\frac{2.25 \mathrm{~T} \tau}{\mathrm{r}_{\mathrm{o}}^{2}}
\end{aligned}
$$

Where:

$$
\begin{array}{ll}
\mathrm{T} & =\text { Transmissivity in square metre per day } \\
\mathrm{S} & =\text { Specific capacity } \\
\mathrm{Q} & =\text { The constant rate of pumpage (metre per day) } \\
\Delta\left(\mathrm{h}_{\mathrm{o}}-\mathrm{h}\right) & =\text { The drawdown per log cycle of distance }(\mathrm{m}) \\
\mathrm{T} & =\text { The time since pumping began (day) }
\end{array}
$$

$\mathrm{r}_{\mathrm{o}} \quad=$ The intercept of the straight line with the zero drawdown axis (m)

Using Equation 1 and 2, the transmissivity of the aquifer was obtained as $86.0 \mathrm{~m}^{2} /$ day while the specific capacity of the well was obtained as 0.258 .

\section{DISCUSSION}

The $\log$ of Fig. 2 shows clearly the presence of five formations which are lateritic sand, clay, fine sand, medium grain sand and coarse sand. The third formation is the formation where most people in the area obtain their drinking water from. This is mostly obtained by hand dug wells which extend in depth from 7 to $9 \mathrm{~m}$. Water from this level will easily be polluted by waste from septic tanks and disposal sites.

Figure 3 shows that the resistivity above $200 \mathrm{ohm}-\mathrm{m}$ is obtained between 8 and $12 \mathrm{~m}$ and also from $20 \mathrm{~m}$ deep. This is an indication of the presence of good quality and yielding aquifer in the area. The spontaneous potential $\log$ as shown in Fig. 4 shows that the quality of the water in the well between 10 and $21 \mathrm{~m}$ is less than what is observed in the deeper part of the well. Figure 3 and 4 therefore shows that the quality of the groundwater increases as you move deeper into the well. The two logs show that the quality of groundwater from the borehole is good. It is however better to source this water beyond a depth of $21 \mathrm{~m}$ to guarantee good quality water.

Analysis of Table 1 showed that the average total dissolved solid in the aquifer is $24.63 \mathrm{gm} / \mathrm{m}^{3}$. This when compared with the maximum permissible limit of 500 $\mathrm{gm} / \mathrm{m}^{3}$ for drinking water, indicate once again that the quality of the aquifer is good (EPA, 2012). The table also showed the calculated values of the conductivity which has an average value of $5.8 \times 10^{-3} \mathrm{mS} / \mathrm{m}$. 
Ochuko Anomohanran / American Journal of Applied Sciences 10 (10): 1263-1269, 2013

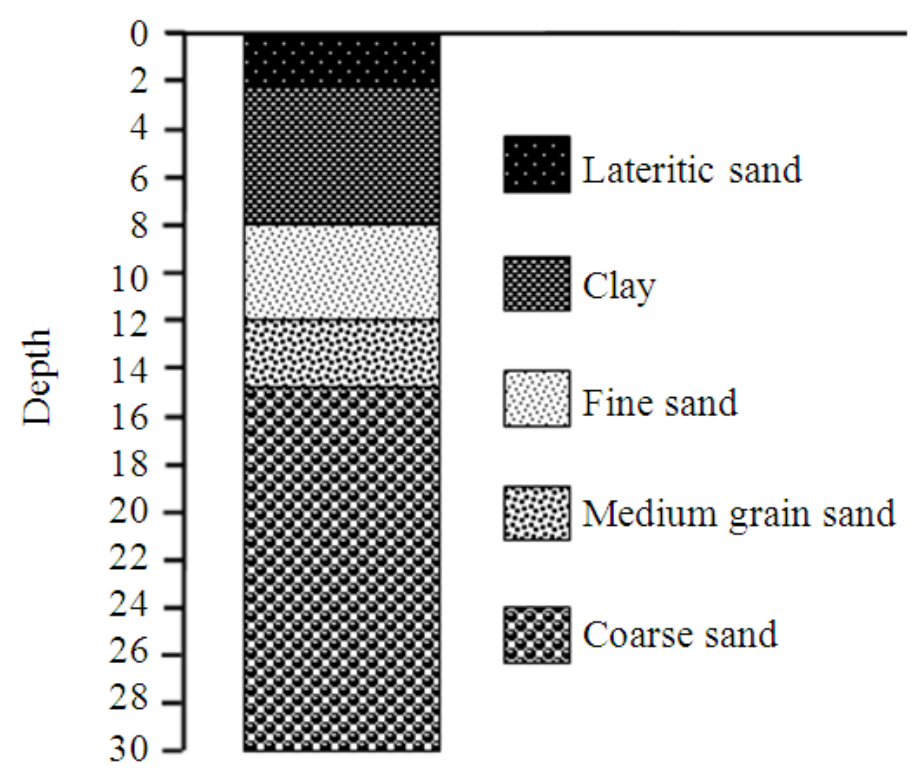

Fig. 2. Lithologic log of the drilled well

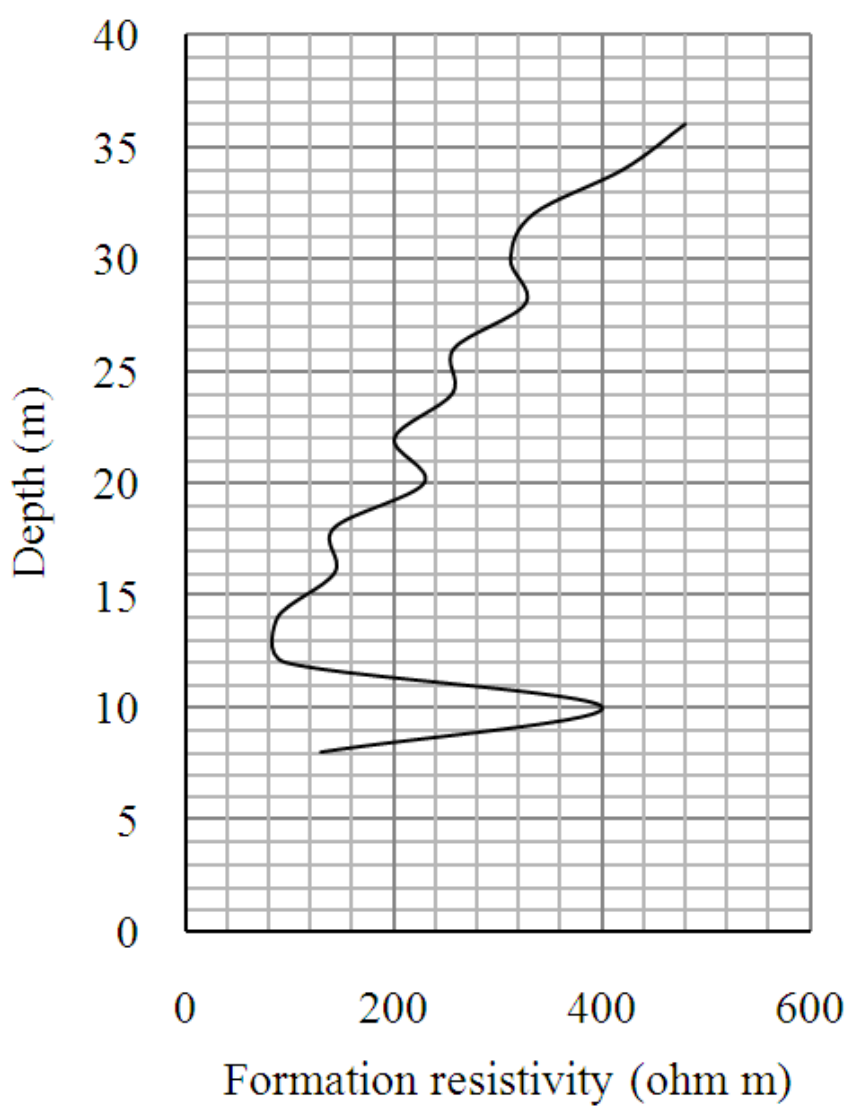

Fig. 3. Electrical resistivity log 
Ochuko Anomohanran / American Journal of Applied Sciences 10 (10): 1263-1269, 2013

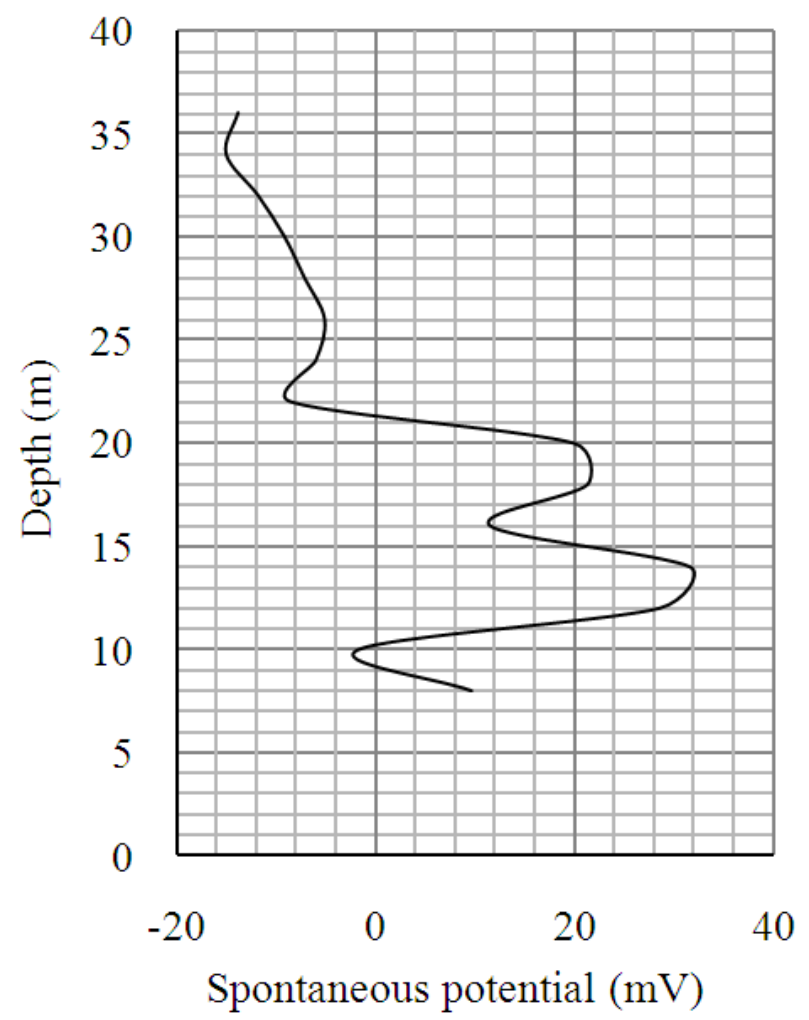

Fig. 4. Spontaneous potential log

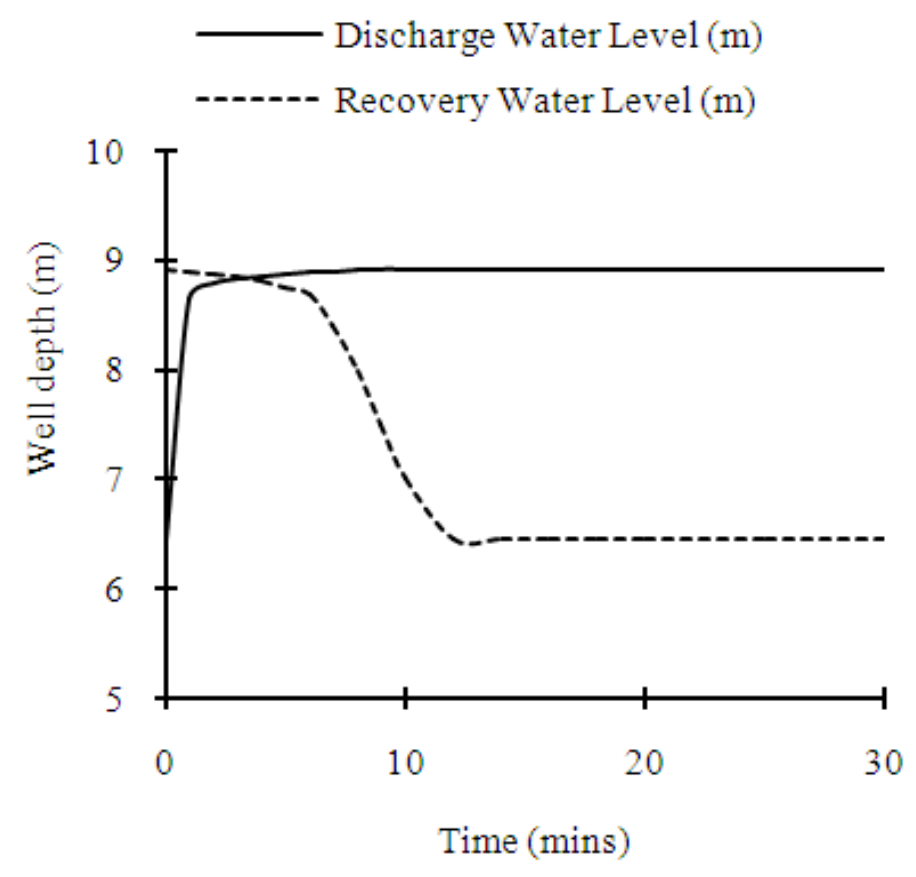

Fig. 5. Record of discharge and recovery period of pumping 


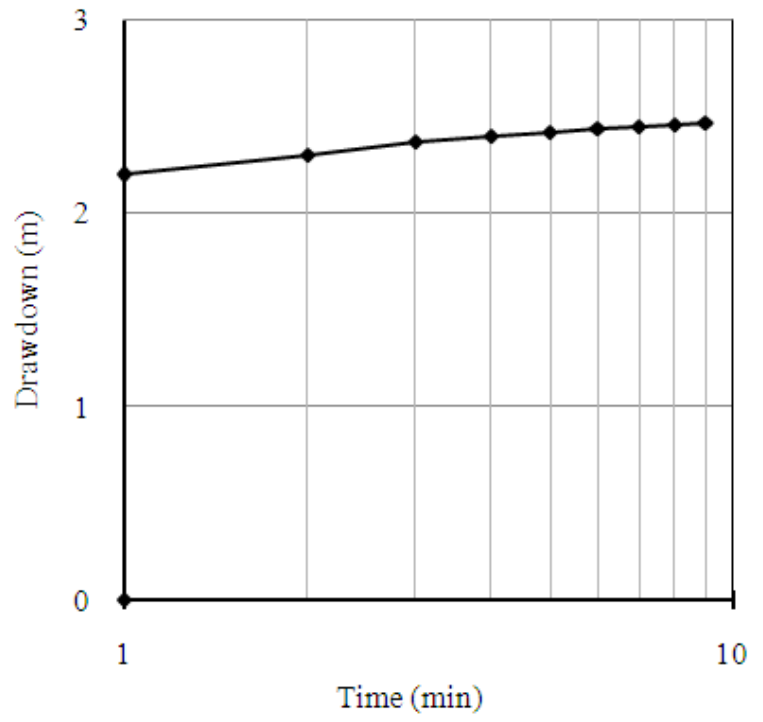

Fig. 6. Plot of drawdown versus time on semi-logarithmic graph

Table 1. Down-hole logging data

\begin{tabular}{lcllll}
\hline & Spontaneous & Formation & Corrected & Total dissolved \\
Depth $(\mathrm{m})$ & potential $(\mathrm{mV})$ & $\begin{array}{l}\text { formation } \\
\text { resistivity }(\mathrm{ohm}-\mathrm{m})\end{array}$ & $\begin{array}{l}\text { Conductivity } \\
(\mathrm{mS} / \mathrm{m})\end{array}$ \\
\hline 8 & 9.63 & 130.20 & 166.20 & 38.51 & 0.0060 \\
10 & 17.25 & 400.00 & 1413.64 & 4.53 & 0.0007 \\
12 & 28.54 & 96.00 & 147.52 & 43.39 & 0.0068 \\
14 & 31.61 & 88.50 & 111.72 & 57.29 & 0.0090 \\
16 & 11.48 & 143.40 & 181.11 & 35.34 & 0.0055 \\
18 & 21.30 & 142.80 & 180.36 & 35.49 & 0.0055 \\
20 & 19.89 & 229.10 & 289.35 & 22.12 & 0.0035 \\
22 & -8.47 & 200.70 & 253.51 & 25.25 & 0.0039 \\
24 & -6.00 & 256.30 & 323.73 & 19.77 & 0.0031 \\
26 & -5.11 & 257.90 & 348.54 & 18.36 & 0.0029 \\
28 & -7.12 & 326.30 & 412.11 & 15.53 & 0.0024 \\
30 & -9.14 & 311.80 & 393.87 & 15.25 & 0.0025 \\
32 & -11.80 & 334.10 & 422.02 & 11.82 & 0.0024 \\
34 & -15.07 & 420.80 & 571.61 & 10.57 & 0.0019 \\
36 & -13.80 & 479.40 & 605.46 & & 0.0017 \\
\hline
\end{tabular}

Figure 5 shows that the discharge reduced linearly for about 2 minutes on a fast note and reduced systematically for another 6 minutes and thereafter remains steady after this time. The recharge also follows the same trend on a reverse note.

The value of the transmissivity obtained using equations 1 and 2 has shown that the aquifer is very prolific (Egbai, 2011). The value of the specific capacity is very useful in identifying problems associated with the well, develop a proper well maintenance procedure or estimate pumping rate or maximum yield of the well.
The hydraulic conductivity of the aquifer which is obtained as $5.8 \times 10^{-3} \mathrm{mS} / \mathrm{m}$ is far less that the United State Environmental Protection Agency recommended standard of $15 \mathrm{mS} / \mathrm{m}$ for drinking water (EPA, 2012). Hence the groundwater from the borehole is safe and useful for domestic purposes as well as other uses.

The values of the hydrologic parameters obtained in this study have shown clearly that the groundwater standard is high as it conforms with the United State Environmental Protection Agency standard for potable water. This implies that the groundwater obtained from 
this area can be used for domestic purposes such as for drinking and cooking. The quality of the water has also shown that it can be used for agricultural purposes such as irrigation and livestock watering as well as for industrial means such as in pharmaceutical and food industries.

The record as shown in Table $\mathbf{1}$ also implies that the deeper one source the groundwater, the higher the quality of water obtained.

The data obtained in this study is not able to determine the groundwater flow direction which is useful in the planning of developmental strategy to protect the groundwater from contamination.

This is why it is important to carry out more hydrologic studies in the area for the purpose of ascertaining the directional flow of the groundwater which will help in identifying the best locations for landfill and dump sites. The essence of this is to maintain the quality of the groundwater.

\section{CONCLUSION}

This study which was aimed at determining the aquifer characteristics of groundwater at Echi was carried out by physical measurements which included spontaneous potential logging, resistivity logging and pumping test. Results which were analysed showed that the conductivity of the aquifer was obtained as $5.8 \times 10^{-3}$ $\mathrm{mS} / \mathrm{m}$. Results further revealed that the transmissivity was obtained as $86.0 \mathrm{~m}^{2} /$ day while the specific capacity of the water was obtained as 0.258 .

The log records and the values of the conductivity and transmissivity have shown that the groundwater is of good quality. This has shown that the groundwater in the study area is suitable for drinking, irrigation, livestock watering and other industrial uses. These findings will act as the bases for the collection of data in this area for groundwater monitoring and development.

\subsection{Appreciation}

The researcher wishes to express his appreciation to Mr. Ese Lucky Ogbemudia and Mr. Emmanuel Urhuar for their assistance rendered in the process of field work.

\section{REFERENCES}

Abdel-Aziz, H., A. Abdel-Gawad and H.A. El-Hadi, 2009. Parameter estimation of pumping test data using genetic algorithm. Proceedings of the 13th International Water Technology Conference, (IWTC 13), Hurghada, Egypt, pp: 823-838.
Alabi, A.A., R. Bello, A.S. Ogungbe and H. O. Oyerinde, 2010. Determination of ground water potential in Lagos State University, Ojo using geoelectric methods (vertical electrical sounding and horizontal profiling). Report Opinion, 2: 68-75.

Anomohanran, O., 2013a. Geophysical investigation of groundwater potential in Ukelegbe, Nigeria. J. Applied Sci., 13: 119-125. DOI: 10.3923/jas.2013.119.125

Anomohanran, O., 2013b. Investigating the geoelectric response of water saturated and hydrocarbon impacted sand in the vicinity of petroleum pipeline. Int. J. Applied Sci. Technol., 3: 14-21.

Egbai, J.C., 2011. Vertical electrical sounding for the determination of aquifer transmissivity. Aus. J. Basic Applied Sci., 5: 1209-1214.

EPA, 2012. Drinking water standards and health advisories. United State Environmental Protection Agency, EPA 822-S-12-001.

Kamble, R.K., G.A. Panvalkar and S. Bhowmick, 2012. Electrical resistivity logging for assessing nature of foundation at Kaiga nuclear power plant. J. Indus. Geophys. Union, 16: 161-167.

Kamble, R.K., R. Rani., N. Ghaosh and G.A. Panvalkar, 2009. Acoustic and electrical logging for evaluation of resistivity and shear and compressional wave velocities of foundation of Kakrapur Nuclear plant. Proceedings of the 33rd Annual Convention and Seminar on Exploration Geophsica, (ACSEG' 09).

Khalil, M.A., E.C. Ramalho and F.A.M. Santos, 2011. Using resistivity $\operatorname{logs}$ to estimate hydraulic conductivity of a Nubian sandstone aquifer in southern Egypt. Near Surface Geophys., 9: 1-7. DOI: $10.3997 / 1873-0604.2011009$

Majumdar, R.K. and D. Das, 2011. Hydrological characterization and estimation of aquifer properties from electrical sounding data in Sagar Island region, South 24 Parganas, West Bengal, India. Asian J. Earth Sci., 4: 60-74.

Uto, A.U., B.I. Odoh and A.U. Okoro, 2012. Estimation of aquifer transmissivity using dar zarrouk parameters derived from surface resistivity measurements: A Case History from Parts of Enugu Town (Nigeria). J. Water Resource Protect., 4: 993 1000. DOI: $10.4236 /$ jwarp.2012.412115 